\title{
Personal Characteristics of e-Bike Riders and Illegal Lane Occupation Behavior
}

\author{
Changxi Ma $\mathbb{D}^{1},{ }^{1}$ Jibiao Zhou $\left(\mathbb{D},{ }^{2,3}\right.$ Dong Yang, ${ }^{1}$ Fuquan Pan, ${ }^{4}$ and Yuanyuan Fan ${ }^{1}$ \\ ${ }^{1}$ School of Traffic and Transportation, Lanzhou Jiaotong University, Anning West Rd. \#88, Anning District, \\ Lanzhou 730070, China \\ ${ }^{2}$ Department of Transportation Engineering, Tongji University, Caoan Rd. \#4800, Shanghai 201804, China \\ ${ }^{3}$ Intelligent Transport System (ITS) ReD Center, Shanghai Urban Construction Design and Research Institute (Group) Co., Ltd., \\ Dongfang Rd. \#3447, Pudong New Area, Shanghai 200125, China \\ ${ }^{4}$ School of Mechanical and Automotive Engineering, Qingdao University of Technology, Changjiang Middle Rd. \#2, \\ Qingdao 266520, China
}

Correspondence should be addressed to Changxi Ma; machangxi@mail.lzjtu.cn and Jibiao Zhou; zhoujibiao@tongji.edu.cn

Received 14 July 2019; Revised 19 December 2019; Accepted 9 June 2020; Published 27 June 2020

Academic Editor: Cherif Larouci

Copyright (C) 2020 Changxi Ma et al. This is an open access article distributed under the Creative Commons Attribution License, which permits unrestricted use, distribution, and reproduction in any medium, provided the original work is properly cited.

\begin{abstract}
This study aimed to reveal the potential relationship between personal characteristics of e-bike riders and illegal occupation of motor vehicle lane. To this end, a questionnaire survey was conducted and 350 valid copies of responses were retrieved from the e-bike riders. Depending on the number of motor vehicle lanes occupied, the risky behavior of illegal occupation was divided into four intervals: intervals A, B, C, and D. The disaggregate theory has high adaptability to the analysis of individual traffic behavior. In this study, the multinomial logit model was used, and eight personal characteristics of e-bike riders were selected. The aforementioned four intervals were the four selection limbs, and a measurement model calculating the influence of personal characteristics on the behavior of illegal occupation was built. The theory of elasticity was employed to analyze the sensitivity degree of each influence factor. The results showed that the absolute values of elasticity of all tested influence factors, including age, educational level, and eye vision, were less than 1.000. However, on the four intervals, the elasticity of riders' temperament was $1.203,1.656,1.554$, and 1.355 , respectively, and elasticity of riding proficiency was $2.782,3.883,3.453$, and 2.932 , respectively.
\end{abstract}

\section{Introduction}

e-bike is defined as the mass of the whole vehicle shall not exceed $55 \mathrm{~kg}$, the speed shall not exceed $25 \mathrm{~km} / \mathrm{h}$, and the motor power shall be $400 \mathrm{~W}$. It strengthens the requirements of riding ability and must have foot riding device, tamper proof, fire-retardant device, waterproof ability, charging protection device, etc. [1].

In recent years, many large- and medium-sized cities of China have witnessed the growing prevalence of e-bikes for daily transport due to their low cost, convenience, and flexibility of riding [1-4]. Unlike North America and Europe, the e-bike has already become one of the most popular modes of transportation, for example, for daily commuting, and not for leisure only. The China Bicycle
Association [5], in 2017, reported that e-bike ownership in China amounted to 250 million. The annual production of e-bikes was 30.97 million, and the export volume was 7.301 million with an export value of US $\$ 1.44$ billion. In some cities, such as Nanning, Haikou, Kunming, and Guilin, the number of e-bikes has far exceeded that of conventional bikes [1,3-5]. For example, e-bikes in the urban area of Nanning amounted to more than 1.8 million [6]. Nanning is the Chinese city with the greatest number of e-bikes and hence known as the city on an e-bike. Apparently, the e-bike has already become an important commuting tool $[7,8]$.

In spite of this, the rapid increase in the number of e-bikes has given rise to a series of safety problems. Besides conventional bike riders and pedestrians, e-bike riders are also a disadvantaged group. Because of their fast traveling 
speed, e-bikes also have a high risk of serious accidents. According to the 2015 China Statistical Yearbook on Road Traffic Accidents, the number of e-bike accidents was 8.2fold that of bike accidents and 5.4-fold that of pedestrian accidents $[9,10]$. From January to June 2016, the number of e-bike accidents in Jiangsu accounted for $70 \%$ of the national total [11]. Further, data on hospital admissions related to e-bike accidents are also bleak. As indicated by hospitalization records of e-bike riders in Hefei from 2009 to 2011, one-third of the e-bike riders were seriously wounded $[1,2,12]$. According to the hospitalization records of Suzhou from October 2010 to April 2011, the number of people injured during e-bike accidents accounted for $57.2 \%$ of all hospital admissions due to road traffic accidents [12]. Both the seriousness and the number of e-bike accidents have increased. According to statistics $[13,14]$, the number of deaths due to e-bikes nationwide was 73 and 1305 in 2011 and 2016, respectively, indicating an increase by $78.02 \%$ in 5 years. The number of people injured during e-bike accidents was 8532 and 16,944, respectively, which was an increase by $14.71 \%$. Given such frequency and seriousness, Guangzhou, Shenzhen, Wenzhou, and Fuzhou have banned or restricted the use of e-bikes $[3,4,8,10,14-18]$. Based on the statistical analysis of accident data and causes, Ren et al. [17] proposed a classification into 12 risky behaviors of riding: illegal occupation of lanes, riding in the opposite direction, riding through a red light, riding overspeed, riding while drunk, turning around the corner at a fast speed, crossing the road abruptly, riding in parallel, riding while making telephone calls, riding with music on, riding while chatting, and riding with someone else on the bike. The results showed that illegal occupation of lanes and riding with someone else on the bike were associated with the highest probability of traffic accident.

The safety problem of e-bike riding has drawn increasing attention, necessitating the need to understand the relationship between personal characteristics of e-bike riders and risky behaviors of riding, especially the relationship between personal characteristics and illegal occupation of lanes. The present study attempted to reduce the occurrence probability of e-bike accidents and raise the safety awareness of e-bike riders. The results shed some light on improving road traffic safety and reducing road traffic accidents.

\section{Literature Review}

Questionnaire survey [1-3, 18-28] and video capture $[16,29-32]$ were the two most commonly used methods in this study to collect data on risky behaviors of e-bike riding. The questionnaires were usually designed based on the previous behavioral studies of light motorcycle and motorcycle riders and car drivers. Most of the research programs use light motorcycle rider behavior questionnaire designed by Yao and $\mathrm{Wu}$ [18], motorcycle rider behavior questionnaire designed by Steg and Brussel [22], and Chinese riding behavior questionnaire designed by Elliott et al. [23]:
(1) The questionnaire survey approach has been widely used in traffic safety studies for collecting information about the riding behavior, safety attitude, and risk perception [18, 21-28]. For example, Ma et al. [21] examined the relationship between electric bike riders' individual characteristics and their riding speed using a questionnaire-based method. Yao and $\mathrm{Wu}$ [18] studied the risk factors involved in e-bike accidents based on the questionnaire survey and determined the relationship between safety attitude, risk perception, and aberrant riding behavior. Steg and Brussel [22] developed a light motorcycle rider behavior questionnaire and confirmed the distinctions between wrong, faulty, and illegal behaviors of light motorcycle riders in Holland. Elliott et al. [23] developed motorcycle driver behavior questionnaire (DBQ) and identified the differences between Britain's traffic errors, control errors, speed violation, and stunt and safe use of motorcycle. Similar studies have also been found in [24-27]. Reason et al. [28] proposed the logical framework for assessing aberrant riding behaviors and designed the DBQ, which differentiated between three types of behaviors: wrong behavior (failure of planned action to achieve the desired effect), mistaken behavior (deviation of behavioral intention from intention), and illegal behavior (intentional deviation from normal safe behavior or socially recognized code of conduct). The revised versions of DBQ have also been used to study aberrant behaviors of two-wheeled vehicle riders, for example, motorcycle riders and light motorcycle riders.

(2) The video capture approach uses the electronic monitoring devices on road and observes the riding behaviors and features of e-bike riders. This method was featured by the massiveness of data. Zhou et al. [16] employed Global Eyes Network video monitoring technology of China Telecom to acquire realtime video data of e-bikes in Ningbo. The major factors influencing the waiting endurance time of e-bike riders were observed. It was found that weather, with or without a pedestrian crosswalk, and law enforcement by traffic police had the largest influence. Konstantina [29] observed 90,000 e-bike riders at 6 monitoring sites in Iowa and studied the influence of road conditions, geographical position, and weather on the use of helmet among riders. Truong et al. [30] observed 26,000 motorcycle and e-bike users and concluded that the use of cell phone while riding correlated to motorcycle type and age. Huan et al. [31] used video monitoring data at road intersections to establish a model that analyzed the factors influencing the waiting endurance time and red-light running behavior of e-bike riders at the intersections. They found that the smaller the number of e-bike riders or the larger the number of motor vehicles at the intersection, the lower the frequency of red-light running behavior among the 
riders. Du et al. [32] performed an observation of 18,000 e-bike riders at intersections in Suzhou and summarized the risky riding behavior.

Many risky riding behaviors are seen among e-bike riders. Traffic violation behaviors are prevalent among e-bike riders. Aberrant riding behaviors usually include the illegal occupation of lanes (Figure 1), overspeeding, red-light running, riding in an opposite direction, and riding with someone else on the e-bike. For example, Du et al. [12] focused on the riding behavior of e-bike riders and reported that riding with someone else on the e-bike, illegal occupation of lanes, red-light running, riding in an opposite direction, and making phone calls while riding were risky riding behaviors. Zhao et al. [33] investigated the risky riding behaviors of e-bike riders and conducted a 4-day survey in Jinhua, China. The results showed that overspeeding, riding with someone else on the e-bike, red-light running, and riding in the opposite direction were among the major risky riding behaviors. Wu et al. [34] investigated the relationship between riding behavior, age, and gender based on the survey data. It was found that young and middle-aged adults were more prone to red-light running compared with elderly people and that male had a higher probability of red-light running compared with female. This was especially true among male riders of battery vehicles with higher dynamic performance. Schepers et al. [35] showed that the seriousness of e-bike accidents far exceeded that of ordinary bike accidents.

Moreover, after correction for riders' age, gender, and bike use frequency, e-bike riders were more likely to be involved in a serious traffic accident. Petzoldt et al. [36] studied the differences between ordinary bikes and e-bikes in traffic conflicts through 80 volunteers. Insignificant differences were reported between the two, but at the intersections, the number of traffic conflicts involving e-bikes was twice that of ordinary bikes. Moreover, the traveling speed was higher for e-bikes upon traffic conflict, and the probability of traffic accidents was also higher. e-Bike riders are an emerging traffic population, and it takes more time for other road users to get used to it. Johnson and Rose [37] performed an online survey on e-bike use among elderly people aged more than 65 years in Australia. It was found that elderly people were more familiar with the safety knowledge of e-bike use and riding and that $84.1 \%$ of elderly riders did not get involved in any e-bike accidents. Hu et al. [15] discussed the factors influencing e-bike traffic accidents in Hefei. The results showed that riders' age, gender, and type of e-bike had a significant impact on traffic accidents. Cherry et al. [38] analyzed the illegal behaviors of e-bike riders and found that overspeeding, red-light running, and overloading were also the major causes of traffic accidents. Moreover, the high frequency of e-bike traffic accidents was closely related to losing control on e-bikes while getting onto the road. For example, Xing et al. [39] performed a roadside observation of risky behaviors of e-bike riders in a city in Anhui province. They found that riders had an average traveling speed of $24 \mathrm{~km} / \mathrm{h}$ at different time intervals within a day and that $74.60 \%$ of riders had a traveling speed of more than $20 \mathrm{~km} / \mathrm{h}$. Zhou et al. [16] studied e-bikes crossing the intersections illegally at a red light. The influence was analyzed. The results showed that three factors, namely, weather, length of a pedestrian crosswalk, and no law enforcement by traffic police, had the greatest influence on the waiting endurance time.

Taken together, extensive studies $[1-3,18,21,40-43]$ have been conducted on riding behaviors of e-bike riders, which contribute to the riding safety of e-bikes. However, fewer studies have been carried out concerning the relationship between personal characteristics of e-bike riders and risky riding behaviors, especially illegal occupation of lanes. However, many traffic accidents are caused by the illegal occupation of lanes by e-bike riders, and such behavior poses a great threat to life and property safety of the riders $[12,18,21,31,33,44]$. This study analyzed whether personal characteristics of riders were directly related to illegal occupation of lanes. The disaggregate theory was used, and a measurement model for assessing the influence of each personal characteristic of riders on illegal occupation of lanes was established. The relationship between each influencing factor and illegal occupation of lanes was quantified, and sensitivity analysis was performed. By conducting a systematic study on the influence degree and mechanism, the influence of personal psychology and psychological properties of riders on the riding behaviors was analyzed from the perspective of traffic psychology. This study can enrich the systematic theory on e-bike riders and lay a theoretical basis for curbing the behavior of illegal occupation of lanes. This will further promote the riding safety and efficiency of e-bike riders.

\section{Data Collection and Processing}

\subsection{Data Collection}

3.1.1. Survey Design. A questionnaire on personal characteristics of e-bike riders was designed. Then, with the help from traffic police, data were collected by field sampling. The specific process was as follows: the traveling speed of the samples (i.e., e-bike riders) was acquired with a radar speed detector. Then, in the downstream road section $200 \mathrm{~m}$ away, the e-bike rider was stopped with the help of traffic police. This rider was then informed of the purpose of the questionnaire survey and received the questionnaire. If the rider was not cooperative, the sample was dropped. The road sections surveyed were two-way six-lane roads; bus stops and intersections were avoided to reduce the influence of other traffic-related factors on e-bike riders. The actual road conditions and the length of road section chosen from the survey are shown in Figure 2.

Demographic information included sex, age, driving age, and educational level. Participants were also asked to report their character, occupation, riding proficiency, and eye vision.

3.1.2. Speed Selection Behavior. According to the requirements in the safety technical specification for electric bicycle 


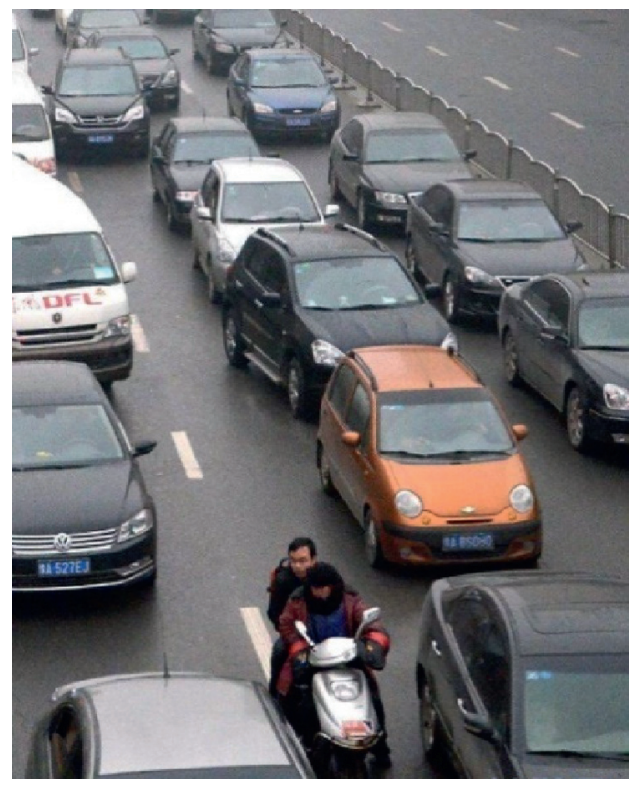

(a)

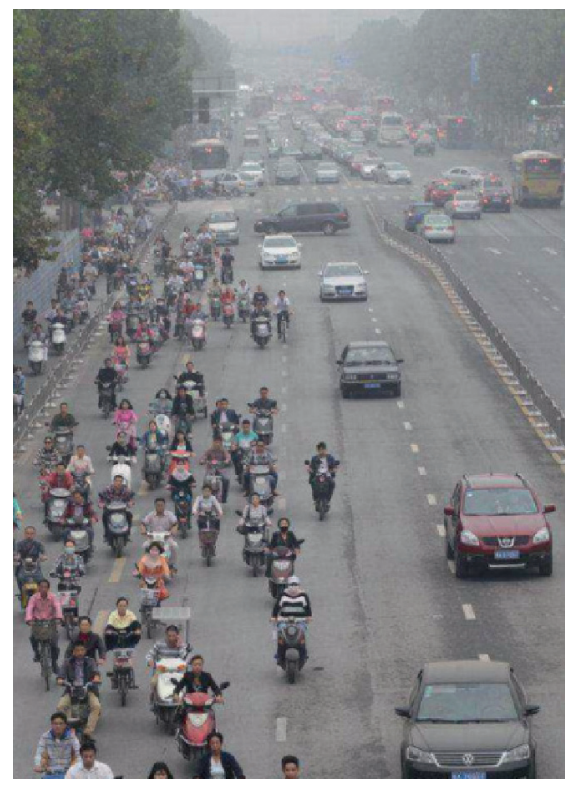

(b)

FIGURE 1: Riding behavior of illegal occupation (IO). (a) One e-bike involves IO. (b) Multiple e-bikes involve IO.

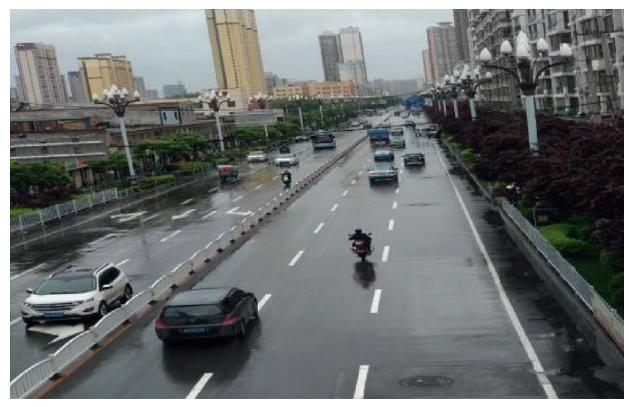

(a)

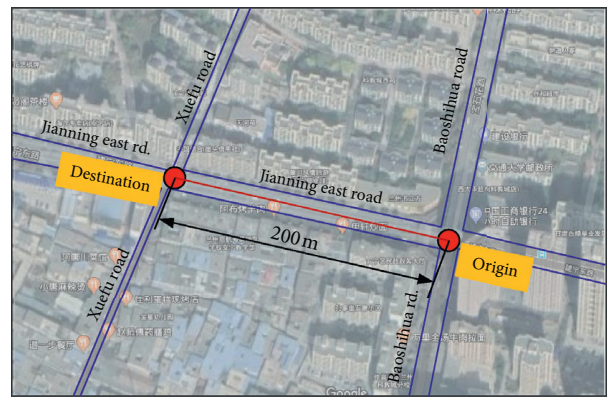

(b)

Figure 2: Actual road conditions and the length of road section chosen for the survey. (a) Actual road conditions. (b) Length of road section.

[45], the traveling speed of e-bikes of more than $25 \mathrm{~km} / \mathrm{h}$ on an urban road was considered as overspeed. Thus, the speed limit for choosing the overspeeding of samples was set as $25 \mathrm{~km} / \mathrm{h}$. To more reasonably study the influence of personal characteristics of riders on their behavior of illegal occupation of lanes based on survey data, the lanes occupied were divided into four categories: nonmotor vehicle lane, first motor vehicle lane, second motor vehicle lane, and third and higher motor vehicle lane, each one represented by intervals A, B, C, and D, respectively. Thus, the numbers of riders occupying different lanes were calculated. The specific interval division diagram is shown in Table 1. The relationship between riders' personal characteristics, traveling speed, and occupation of motor vehicle lane was discussed using survey data. To do this, the average traveling speed of e-bike riders was acquired for the road section concerned. According to the limit on the traveling speed of e-bike riders and actual distribution of speed data for the road section, the traveling speed of the riders was divided into four intervals, namely,
$0-15,15-25,25-35$, and $35 \mathrm{~km} / \mathrm{h}$ and above, which were represented by $A, B, C$, and $D$, respectively. Using the survey data, the number of riders within each speed interval and average traveling speed were calculated.

Four intervals, A, B, C, and D, corresponding to different lane occupation behaviors, were the four selection limbs of the mode, the values of which were $0,1,2$, and 3 , respectively. The personal characteristics as influencing factors for the selection of lane occupation behavior were assessed and identified, as shown in Table 2.

3.2. Data Processing. The subjects surveyed were e-bike riders, and a total of 352 copies of responses were retrieved. Among these, 350 copies were found to be valid after screening. According to the statistics, 311 were male riders (88\%) and 41 were female riders (12\%). They were 18-61 years old, and they all had more than 1 year of driving age. Statistics of the personal characteristics of e-bike riders are shown in Table 3. 
TABLE 1: Interval division diagram of road lanes occupied by e-bike riders.

\begin{tabular}{lcccc}
\hline Middle isolation zone & Third motor vehicle lane & Second motor vehicle lane & First motor vehicle lane & Nonmotor vehicle lane \\
\hline Middle isolation zone & Interval D & Interval C & Interval B & Interval A \\
Middle isolation zone & $35 \mathrm{~km} / \mathrm{h}$ and above & $25-35 \mathrm{~km} / \mathrm{h}$ & $15-25 \mathrm{~km} / \mathrm{h}$ & $0-15 \mathrm{~km} / \mathrm{h}$ \\
\hline
\end{tabular}

TABLE 2: Influencing factors.

\begin{tabular}{|c|c|c|}
\hline Influencing factor & Variable & Explanation \\
\hline Gender & $X_{1}$ & 1 for male and 0 for female \\
\hline Age & $X_{2}$ & $\begin{array}{c}\text { Classified into four age groups: } 18-30 \text { years, } 30-45 \text { years, } 45-60 \text { years, and older than } 60 \text { years, assigned } \\
\text { with values } 0,1,2 \text {, and } 3 \text {, respectively }\end{array}$ \\
\hline Educational level & $X_{3}$ & $\begin{array}{c}\text { Classified into four levels: primary school and lower, junior high school, senior high school, and } \\
\text { university and higher, assigned with values } 0,1,2 \text {, and } 3 \text {, respectively }\end{array}$ \\
\hline Driving age & $X_{4}$ & $\begin{array}{c}\text { Classified into four levels: } 1 \text { year or less, } 1-3 \text { years, } 3-5 \text { years, and more than } 5 \text { years; the values are } 0,1,2 \text {, } \\
\text { and } 3 \text {, respectively }\end{array}$ \\
\hline $\begin{array}{l}\text { Character } \\
\text { (temperament) }\end{array}$ & $X_{5}$ & $\begin{array}{c}\text { Classified into four types: melancholic, phlegmatic, sanguineous, and choleric, assigned with values } 0,1 \text {, } \\
\qquad 2 \text {, and } 3 \text {, respectively }\end{array}$ \\
\hline Occupation & $X_{6}$ & $\begin{array}{c}\text { Classified into four groups: students, in-service staff, self-employed, and retirees (other), assigned with } \\
\text { values } 0,1,2 \text {, and } 3 \text {, respectively }\end{array}$ \\
\hline Vision correction & $X_{7}$ & Dummy variable: 1 for yes, 0 for no \\
\hline Cycling proficiency & $X_{8}$ & $\begin{array}{l}\text { Classified into four levels: novice, moderately skilled, skilled, and highly skilled, assigned with values } 0 \text {, } \\
\qquad 1,2 \text {, and 3, respectively }\end{array}$ \\
\hline
\end{tabular}

TABLE 3: Statistics of personal characteristics of e-bike riders.

\begin{tabular}{|c|c|c|c|c|c|c|c|c|}
\hline \multirow{3}{*}{$\begin{array}{l}\text { Personal characteristic } \\
\text { Gender } \\
\text { Age }\end{array}$} & \multicolumn{8}{|c|}{ Number of e-bike riders } \\
\hline & \multicolumn{3}{|c|}{ Male } & 310 & \multicolumn{3}{|c|}{ Female } & 40 \\
\hline & $18-30$ years & 108 & $30-45$ years & 142 & $45-60$ years & 81 & 60 years and more & 19 \\
\hline Educational level & Primary school and lower & 27 & Junior high school & 121 & Senior high school & 157 & University and higher & 45 \\
\hline Driving age & Below 1 year & 21 & $1-3$ years & 180 & $3-5$ years & 122 & 5 years and more & 27 \\
\hline $\begin{array}{l}\text { Character } \\
\text { (temperament) }\end{array}$ & Melancholic & 1 & Lymphatic & 129 & Sanguine & 149 & Bilious & 71 \\
\hline Occupation & Student & 11 & Employee & 179 & Freelancer & 141 & Retiree & 19 \\
\hline Vision correctio & Corr & cted & & 284 & & t corr & ted & 66 \\
\hline Riding proficiency & Very skillful & 130 & Skillful & 189 & Moderately skillful & 25 & Novice & 6 \\
\hline
\end{tabular}

Data on average traveling speed and specific lanes occupied by the e-bike riders are shown in Tables 4 and 5, respectively.

\subsection{Reliability and Validity Tests}

3.3.1. Reliability Test. Reliability test can well reflect the reliability of data sources of the questionnaire survey and is considered an indispensable step before formal data analysis. The higher the reliability of the survey data, the more reliable the conclusions drawn from data analysis. The results of reliability test are usually represented by three indicators, namely, Cronbach's alpha, Guttman's coefficient, and splithalf coefficient. In the questionnaire used in this study, some items were scored in multiple ways, and so internal consistency of the questionnaire was assessed by Cronbach's $\alpha$ :

$$
\alpha=\left(\frac{k}{1-k}\right)\left(1-\frac{\sum_{i=1}^{k} S_{i}^{2}}{S_{x}^{2}}\right)
$$

where $k$ is the number of items contained in the questionnaire; $S_{i}^{2}$ is the variance of score of the $i$ th item (measured value); and $S_{x}^{2}$ is the variance of the total questionnaire
TABle 4: Traveling speed of e-bike riders.

\begin{tabular}{lcccc}
\hline Interval of speed selection & $\mathrm{A}$ & $\mathrm{B}$ & $\mathrm{C}$ & $\mathrm{D}$ \\
\hline Number of riders & 10 & 133 & 147 & 60 \\
Average riding speed & 13.3037 & 20.7137 & 28.8339 & 40.7376 \\
\hline
\end{tabular}

score. The increased content of reliability test is as follows: note that the reliability coefficient is closely related to the number of items $(k)$ of the scale; the more the number of items, the greater the acceptable reliability. For a scale with about 10 questions, if the coefficient of $\alpha$ reaches 0.7 , the reliability is good [46].

The SPSS 19.0 software was used to verify the reliability of data from the questionnaire survey. It was found that Cronbach's alpha was more than 0.807 for three potential variables, namely, riding proficiency, occupation, and temperament. The overall reliability of eight variables was 0.722 indicating that the reliability of the questionnaire was good; that is, the questionnaire was acceptable in the overall design.

3.3.2. Validity Test. Validity consists of content validity, criterion validity, and construct validity, and construct 
TABLE 5: Lanes illegally occupied by e-bike riders.

\begin{tabular}{lcccc}
\hline $\begin{array}{l}\text { Interval for different lanes } \\
\text { occupied }\end{array}$ & $\begin{array}{c}\text { A } \\
\text { Nonmotor vehicle } \\
\text { lane }\end{array}$ & $\begin{array}{c}\text { First motor vehicle } \\
\text { lane }\end{array}$ & $\begin{array}{c}\text { Second motor vehicle } \\
\text { lane }\end{array}$ & $\begin{array}{c}\text { Third and higher motor vehicle } \\
\text { lane }\end{array}$ \\
\hline Number of riders & 91 & 177 & 49 & 33 \\
\hline
\end{tabular}

validity is a measure of the degree of agreement between practice and theory. Factor analysis is the most commonly used method for demonstrating construct validity. However, many problems in reality not only involve multiple variables but also intricate connections between the variables. The best way is to extract a few synthetic variables that contain the majority of information in the original variables. Moreover, these synthetic variables should be mutually independent. Factor analysis is an ideal method to derive synthetic variables so that the relationship between multiple variables can be depicted using a few factors. Variables described are usually actually observed random variables, while the synthetic variables are unobservable ones. In actual application, these factors are known as common factors. The personal characteristics of riders identified by the questionnaire survey as related to illegal occupation of lanes were consistent with the common factors found by factor analysis.

The starting point of factor analysis is to represent the majority of the information contained in the original variables by mutually independent variables, which can be expressed by the following mathematical model [46]:

$$
\begin{aligned}
& x_{1}=a_{11} F_{1}+a_{12} F_{2}+\ldots+a_{1 m} F_{m}, \\
& x_{2}=a_{21} F_{1}+a_{22} F_{2}+\ldots+a_{2 m} F_{m}, \\
& \ldots \\
& x_{p}=a_{p 1} F_{1}+a_{p 2} F_{2}+\ldots+a_{p m} F_{m},
\end{aligned}
$$

where $x_{1}, x_{2}, \cdots, x_{p}$ are $p$ original variables, which are standardized variables with a mean of 0 and standard deviation of $1 ; F_{1}, F_{2}, \ldots, F_{m}$ are $m$ factor variables; and $m$ is smaller than $p$. It can be represented in the following matrix form:

$$
X=A F+a \varepsilon,
$$

where $F$ is a common factor, representing $m$ mutually perpendicular coordinate axes in the high-dimensional space, and $A$ is the factor load matrix, the load of the $i$ th original variable on the $j$ th factor variable.

The content of the validity test is as follows: the steps of factor analysis are to (1) determine whether the original variables to be analyzed are suitable for factor analysis; (2) construct factor analysis; (3) use rotation method to make factor variables more interpretable; and (4) calculate factor scores.

In the validity test of the questionnaire, the Kaiser-Meyer-Olkin (KMO) measure of sampling adequacy and the Bartlett test for sphericity were performed to determine whether the questionnaire data were fit for factor analysis. The value of KMO measure was 0.689 , which was greater than 0.50 , and that of Sig was 0.00 , which was less than 0.05 , indicating that the questionnaire was suitable for factor analysis. Principal component analysis is commonly used for factor analysis to test the construct validity of the questionnaire. Principal common factors were extracted from the questionnaire. Three principal components existed with a characteristic root of greater than 1, and the percentage contribution of these three principal components was $29.194 \%, 20.376 \%$, and $12.423 \%$, respectively. The cumulative contribution rate was $61.994 \%$, indicating that the potential variables screened through the test had high construct validity.

\section{Construction of the Behavior Selection Model and Riding Behavior Selection}

4.1. Disaggregate Model. Logit model is a special form of generalized linear regression model. The model itself has few restrictions on data conditions. The independent variable can be continuous variable or unnecessary or orderly classified variable, and the variable is not required to meet the normal distribution. At present, the commonly used logit models are binomial logit regression model, conditional logit regression model, ordered logit regression model, and multiple classified ordered logit regression model. Among them, the ordinal logit model is an extension of binomial logit model, which was proposed by McCullagh in 1980 to analyze the data whose dependent variable is ordinal classified variable. Many studies have found that for classified ordered data, binomial logit model instead of ordered logit model can only achieve $50 \%-70 \%$ of the test efficiency, which shows that multiple classified ordered logit model has a good effect in dealing with classified variable data [23-27].

Individual data were used for model construction and calibration when applying disaggregate theory to analyze individual traffic behaviors. From the 1970s to the present day, a disaggregate model has been widely used in the transportation field and abundant achievements have been made [22-26, 47-51]. It is assumed with the disaggregate model that the travelers may choose the transportation scheme with the maximum utility. The utility function, divided into fixed and random parts, was expressed as follows:

$$
U_{i n}=V_{i n}+\varepsilon_{i n}
$$

where

$$
V_{\text {in }}=\sum_{k=1}^{k} \theta_{k} X_{\text {ink }}
$$

$U_{\text {in }}$ is the utility function of the $i$ th scheme chosen by the $n$th traveler; $V_{i n}$ is the fixed term of $U_{i n} ; \varepsilon_{i n}$ is the random term of $U_{i n} ; k$ is the specific number of attribute variables; $\theta_{k}$ is the 
parameter value of the $k$ th variable; and $X_{\text {ink }}$ is the value of the $k$ th attribute variable of the $i$ th scheme chosen by the $n$th traveler.

In the aforementioned disaggregate model, when $\varepsilon_{i n}$ obeyed the double exponential distribution and multivariate normal distribution, the logit and probit models could be built, respectively. e-bike riders as the principal participants in the transportation system usually show traffic selection behaviors that are hard to capture accurately, thus leading to randomness in the changes of the transportation system. When the e-bike riders choose to occupy the motor vehicle lanes, both personal and environmental factors are responsible for shaping such a choice. However, environmental factors exert a similar influence on all riders, while the selection of behavior of illegal lane occupation displays discreteness. This is mainly due to the varying perception about the environmental factors on the part of riders. That is, the riders develop different perception and occupy different lanes even in the same environment. Thus, personal characteristics have the most decisive impact on the behavior of illegal occupation of motor vehicle lanes. Conventional models cannot reflect the double features of discreteness and nonlinearity of riding behaviors stemming from the personal characteristics of the riders. In contrast, the disaggregate model especially targets these features and is highly adaptive in this field. Furthermore, the behavior of occupying motor vehicle lanes is chosen by the riders after comprehensive consideration of multiple factors in an attempt to achieve maximum expected utility. This conforms to the initial assumption of the disaggregate theory. Therefore, a disaggregate model was applied to analyze the riding behavior selection of e-bike riders.

4.2. Construction of Riders' Behavior Selection Model. A riders' illegal lane occupation behavior selection model was constructed based on the multinomial logit (MNL) theory and valid data of personal characteristics of e-bike riders. Based on the basic form of an MNL model, $\varepsilon_{i n}$ obeyed dual exponential distribution and $\varepsilon_{i n}$ was $V_{\text {in }}$ mutually dependent. Then, the probability of the $n$th rider choosing the $i$ th behavior of illegal lane occupation was expressed as follows:

$$
P_{\text {in }}=\frac{e^{V_{\text {in }}}}{\sum_{i=1}^{I_{n}} e^{V_{i n}}},
$$

where $I_{n}$ is the total number of currently optional behaviors; $P_{i n}$ is the probability that the $n$th rider chooses the $i$ th behavior; $\varepsilon_{\text {in }}$ is the random term of utility function for the $n$th rider choosing the $n$th scheme; and $V_{\text {in }}$ is the fixed term of utility function $U_{i n}$ for the $n$th rider choosing the $i$ th scheme.

The model construction and calculation workflow based on the basic features of riding behavior selection are shown in Figure 3. In the figure, $t$ is the $t$-statistic for each influence factor and $R^{2}$ is the correlation coefficient.

\subsection{Model Solution}

4.3.1. Calibration of Influencing Factors of the Model. The SPSS software was used to calibrate the influencing factors of the model. Table 6 shows that the minimum $t$ statistic (absolute value) was 4.975, which was higher than 1.960 , indicating that the influencing factors were significant.

In the statistical analysis using SPSS, $R^{2}$ was used to measure the degree of fitness of the model and was called correlation coefficient, where $R^{2} \in(0,1)$. The closer the value of $R^{2}$ to 1.000 , the higher the degree of linear regression predictions fitting the data, and the higher the agreement between the built model and actual situation. In this study, the correlation coefficient $R^{2}$ was 0.594 , and the adjusted value of $R^{2}$ was 0.563 , as shown in Table 7, indicating good fitness of the model.

4.3.2. Utility Function. Parameter values of each influencing factor on the four intervals are shown in Table 8. According to Table 8 , the utility functions $V_{0}, V_{1}, V_{2}$, and $V_{3}$ corresponding to intervals $\mathrm{A}, \mathrm{B}, \mathrm{C}$, and $\mathrm{D}$ were, respectively, as follows:

$$
\begin{aligned}
& V_{0}=0.491 X_{1}-0.059 X_{3}+1.030 X_{5}+0.417 X_{6}+1.919 X_{8}, \\
& V_{1}=0.730 X_{2}-0.059 X_{3}+0.334 X_{4}+1.030 X_{5}+0.430 X_{7}, \\
& V_{2}=-0.059 X_{3}+0.334 X_{4}+1.030 X_{5}+0.417 X_{6}+1.919 X_{8}, \\
& V_{3}=0.491 X_{1}+0.730 X_{2}+1.030 X_{5}+0.430 X_{7}+1.919 X_{8} .
\end{aligned}
$$

To determine the relationship between each influencing factor and behavior of illegal lane occupation among e-bike riders, a sensitivity analysis was performed for each influencing factor. The degree of sensitivity is usually represented by elasticity. In the disaggregate theory, when an influencing factor changes, the elasticity $E$ for variation in the probability of riding scheme selection is given by

$$
E=\theta_{k} X_{\text {ink }}\left(1-P_{\text {in }}\right) \text {. }
$$

Elasticity can be positive or negative. When the two variables correlate positively, the elasticity value is positive; otherwise, it is negative. The absolute values of all elasticities of more than 1.000 on the four intervals indicate that the influence factor has elasticity on the selection of illegal lane occupation behavior; otherwise, elasticity is lacking. First of all, the means of personal characteristics of riders on each interval were calculated based on the survey data of personal characteristics and illegal lane occupation behavior of the riders. Next, the parameter values obtained in Table 4 were introduced into (5) and (6), and the probability of selecting illegal lane occupation behavior was calculated. Then, using the calculation (8), the elasticity of each influencing factor for the probability of selecting illegal lane occupation behavior was derived. 


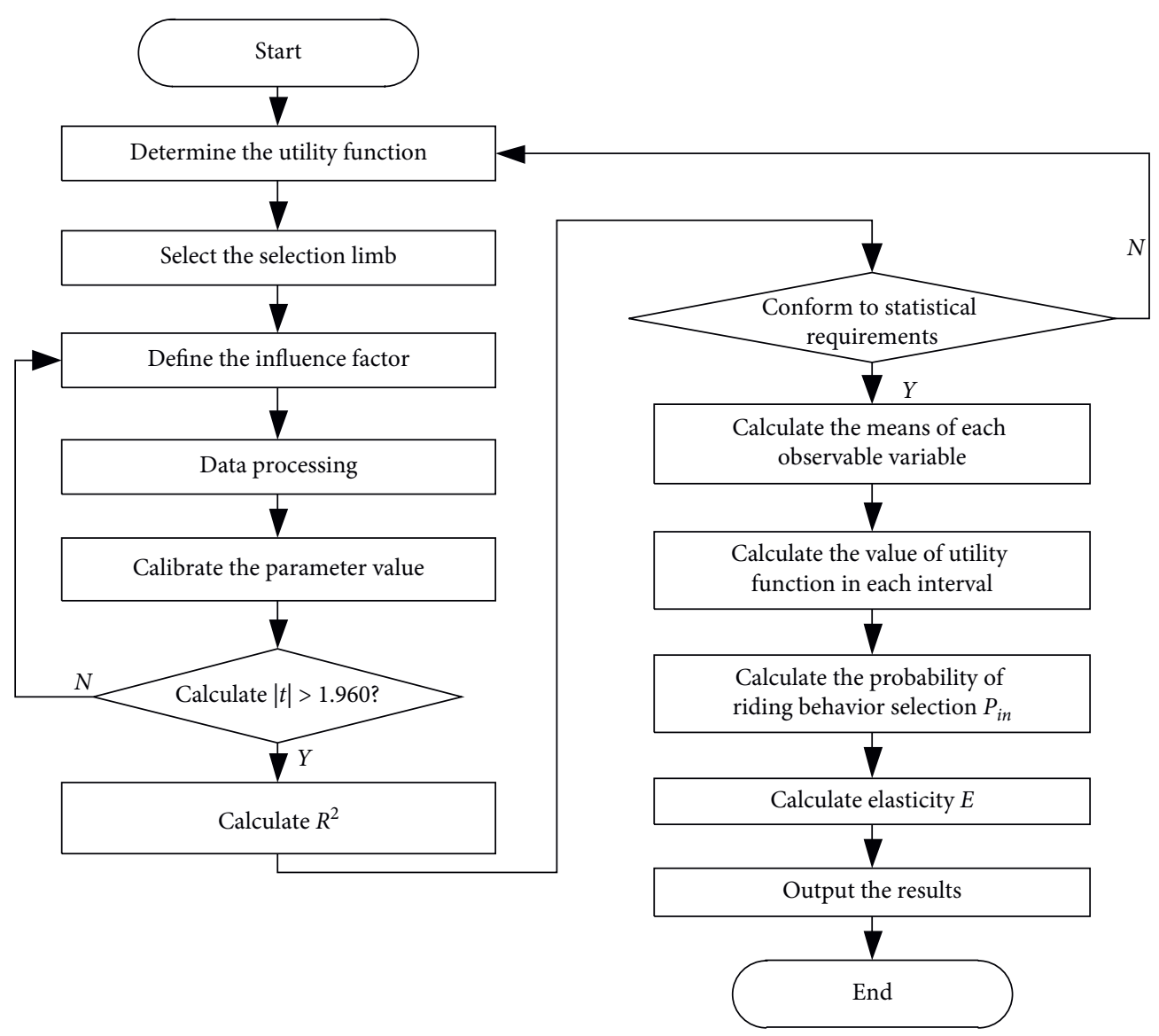

FIgURE 3: Model calculation workflow.

TABLE 6: Calibration of influencing factors of the model.

\begin{tabular}{lcccc}
\hline Influencing factor & Variable & Parameter value & Standard deviation & $t$-Statistic \\
\hline Gender & $X_{1}$ & 0.491 & 0.122 & 16.364 \\
Age & $X_{2}$ & 0.730 & 0.056 & 0.946 \\
Educational level & $X_{3}$ & -0.059 & 0.060 & 11.318 \\
Driving age & $X_{4}$ & 0.334 & 0.066 & 12.581 \\
Temperament & $X_{5}$ & 1.030 & 0.056 & 13.101 \\
Occupation & $X_{6}$ & 0.417 & 0.062 & 18.977 \\
Vision correction & $X_{7}$ & 0.430 & 0.103 & 4.905 \\
Cycling proficiency & $X_{8}$ & 1.919 & 0.061 & 15.619 \\
\hline
\end{tabular}

TABle 7: Degree of fitness of the calibrated model.

\begin{tabular}{lcccc}
\hline Model & $R$ & $R^{2}$ & Adjusted $R^{2}$ & Standard error of estimate \\
\hline 1 & 0.771 & 0.594 & 0.563 & 1.769 \\
\hline
\end{tabular}

TABLE 8: Influencing factors and parameter values.

\begin{tabular}{lcccr}
\hline Influencing factor & Variable & & Interval & $\mathrm{C}$ \\
\hline Gender & $X_{1}$ & 0.491 & $\mathrm{~B}$ & 0.491 \\
Age & $X_{2}$ & -0.059 & 0.730 & 0.730 \\
Educational level & $X_{3}$ & & -0.059 & -0.059 \\
Driving age & $X_{4}$ & 1.030 & 1.030 & 0.334 \\
Character & $X_{5}$ & 0.417 & & 1.030 \\
Occupation & $X_{6}$ & & 0.430 & 0.417 \\
Vision correction & $X_{7}$ & 1.919 & & 1.030 \\
Cycling proficiency & $X_{8}$ & & & 1.919 \\
\hline
\end{tabular}




\section{Results Analysis}

5.1. Relationship between Personal Characteristics and Illegal Lane Occupation of e-Bike Riders. Different riding habits and behaviors were derived from riders with different personal characteristics. Given limited traffic resources (some nonmotor vehicle lanes occupied by motor vehicle lanes), riders are faced with a shortage of nonmotor vehicle lanes. As a result, many nonmotor vehicle riders tend to occupy motor vehicle lanes, and e-bike riders account for a greater proportion. The personal characteristics identified to influence illegal lane occupation by e-bike riders were gender, age, educational level, driving age, temperament, occupation, and road infrastructure of motor vehicle lanes. Therefore, the personal characteristics of e-bike riders were discussed in this study to shed light on the influence of personal characteristics of riders on their behavior of illegal lane occupation.

5.1.1. Gender and Age. Using the method described in Section 4, the selection probability and parameter value of gender and age on different intervals and the means and elasticity of each influencing factor on each interval were evaluated, as shown in Table 9. Similarly, the values corresponding to each influencing factor were also evaluated using this method. In field sampling, $88 \%$ of the e-bike riders were male, while the female riders took up a small proportion of the surveyed area. The probability of illegal lane occupation was more than 0.713 , which was higher than 0.500. Apparently, more than one-half of the e-bike riders would choose to occupy the motor vehicle lanes when traveling. As shown in Table 9, the means for gender on the four intervals increased steadily, and all of them were more than 0.921 and 0.500 for male and female, respectively. That is, male riders outnumbered the female riders. In other words, male riders were more likely to occupy motor vehicle lanes compared with female riders. The values of elasticity for gender on the four intervals were all less than 1.000, indicating the lack of elasticity of gender for the choice of illegal lane occupation behavior. However, the elasticity was 0.391 on interval $\mathrm{B}$, which was higher than that on the other three intervals. This indicated that gender had the greatest impact on the behavior of occupying the first motor vehicle lane.

The means for age on the $\mathrm{B}$ interval is the highest. This meant people aged between 30 and 45 have the highest probability of choosing the illegal lane occupation behavior. This correlated with the personality traits of young people, such as impulsiveness and lack of safety awareness. Elasticity for age was smaller than 1.000 on the four intervals, indicating that age had a low elasticity on the choice of illegal lane occupation behavior. However, elasticity was the highest on interval B (occupying the first motor vehicle lane), the value being 0.693 . This indicated that compared with the other three intervals, age had the most significant impact on the choice of the behavior of occupying the first motor vehicle lane. That is, the younger the age of e-bike riders, the more likely that the riders occupied the motor vehicle lane closer to the middle isolation zone.
5.1.2. Educational Level and Driving Age. Table 10 shows the results on the educational level and driving age. According to the table, the means for the educational level were similar on all the four intervals and changed steadily. The mean was the highest on interval $\mathrm{A}$, the value being 1.681, which suggested that the educational level was the highest among riders occupying the nonmotor vehicle lane. Values of elasticity for educational level were all negative on the four intervals, the absolute value being about 0.070 . On the one hand, this indicated that the educational level had low elasticity for the choice of illegal lane occupation behavior. That is, the educational level did not have a decisive role in the choice of illegal lane occupation behavior. On the other hand, it indicated that fewer riders chose to occupy motor vehicle lanes. This is because a rise in the riders' knowledge level boosted their safety awareness and traffic knowledge. More riders with a high educational level would voluntarily comply with traffic rules, and their behavior of illegal lane occupation decreased.

As shown in Table 10, the mean for driving age was 1.451, and no significant change in the mean was found on the four intervals. However, the mean on interval D was 1.515 , which was slightly higher than that on the other three intervals. This indicated that the longer the driving age, the more likely the riders would occupy the motor lanes close to the middle isolation zone. This was because riders with a longer driving age were more proficient and skillful and more confident with riding. Therefore, these riders were more likely to occupy motor vehicle lanes closer to the middle isolation zone. The mean of elasticity for driving age on the four intervals was 0.364 , which was smaller than 1.000 . This indicated the lack of elasticity of driving age for the choice of illegal lane occupation behavior. Thus, driving age had little impact on the behavior of occupying motor vehicle lanes.

5.1.3. Temperament and Eye Vision. Table 11 shows the results on temperament and eye vision. According to the table, the mean for temperament increased steadily on the four intervals, the mean value being around 1.800. This indicated that the choice of illegal lane occupation behavior varied rather steadily with temperament. As indicated by the means, many of them were of a sanguine temperament. Values of elasticity for temperament on the four intervals were all more than 1.000, indicating high elasticity of temperament for the choice of illegal lane occupation behavior. The elasticity was the highest on interval $\mathrm{B}$, the value being 1.656. This indicated that temperament had the greatest impact on the behavior of occupying the first motor vehicle lane. The specific relationship between temperament and behavior of illegal lane occupation is illustrated in Figure 4.

Figure 4 shows that among riders occupying motor vehicle lanes, those with sanguineous temperament accounted for the highest proportion. Moreover, the largest number of riders with such temperament occupied the nonmotor vehicle lane of all temperaments, followed by phlegmatic temperament. Similarly, as shown in Figure 4, the smallest number of riders with melancholic 
TABLE 9: Calculation results for age and gender.

\begin{tabular}{|c|c|c|c|c|c|c|c|}
\hline \multirow{2}{*}{ Interval for different lanes occupied } & \multirow{2}{*}{ Selection probability } & \multicolumn{3}{|c|}{ Gender } & \multicolumn{3}{|c|}{ Age } \\
\hline & & Parameter value & Mean & Elasticity & Parameter value & Mean & Elasticity \\
\hline $\mathrm{A}$ & 0.287 & 0.491 & 0.835 & 0.292 & 0.730 & 1.022 & 0.532 \\
\hline $\mathrm{B}$ & 0.124 & 0.491 & 0.910 & 0.391 & 0.730 & 1.085 & 0.693 \\
\hline $\mathrm{C}$ & 0.289 & 0.491 & 0.878 & 0.306 & 0.730 & 0.878 & 0.456 \\
\hline $\mathrm{D}$ & 0.300 & 0.491 & 0.879 & 0.302 & 0.730 & 1.061 & 0.542 \\
\hline
\end{tabular}

TABLE 10: Calculation results on the educational level and driving age.

\begin{tabular}{lccccccc}
\hline \multirow{2}{*}{ Interval for different lanes occupied } & \multirow{2}{*}{ Selection probability } & \multicolumn{2}{c}{ Educational level } & \multicolumn{3}{c}{ Driving age } \\
& & Parameter value & Mean & Elasticity & Parameter value & Mean & Elasticity \\
\hline A & 0.287 & -0.059 & 1.681 & -0.071 & 0.334 & 1.341 & 0.319 \\
B & 0.124 & -0.059 & 1.616 & -0.083 & 0.334 & 1.480 & 0.433 \\
C & 0.289 & -0.059 & 1.633 & -0.068 & 0.334 & 1.469 & 0.349 \\
D & 0.300 & -0.059 & 1.545 & -0.064 & 0.334 & 1.515 & 0.354 \\
\hline
\end{tabular}

TABLE 11: Calculation results on temperament and eye vision.

\begin{tabular}{lccccccc}
\hline \multirow{2}{*}{ Interval for different lanes occupied } & \multirow{2}{*}{ Selection probability } & \multicolumn{2}{c}{ Temperament (character) } & \multicolumn{3}{c}{ Vision correction } \\
& & Parameter value & Mean & Elasticity & Parameter value & Mean & Elasticity \\
\hline A & 0.287 & 1.030 & 1.637 & 1.203 & 0.430 & 0.209 & 0.064 \\
B & 0.124 & 1.030 & 1.836 & 1.656 & 0.430 & 0.186 & 0.070 \\
C & 0.289 & 1.030 & 2.122 & 1.554 & 0.430 & 0.184 & 0.056 \\
D & 0.300 & 1.030 & 1.879 & 1.355 & 0.430 & 0.152 & 0.046 \\
\hline
\end{tabular}

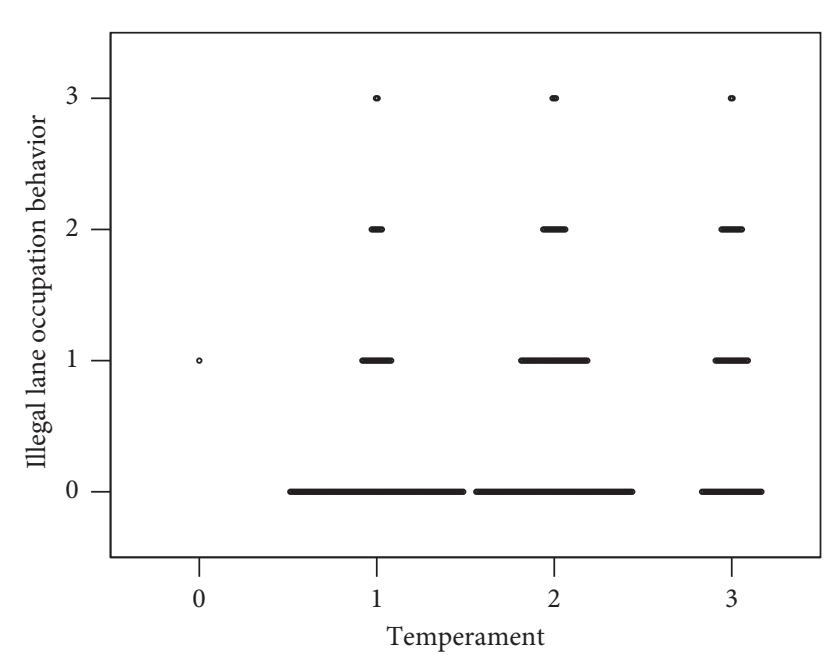

Figure 4: Relationship between temperament and illegal lane occupation behavior.

temperament chose such illegal behavior. Apparently, the number of riders with phlegmatic and sanguineous temperaments was the highest among all temperaments. Moreover, riders with sanguineous temperament were more likely to choose the behavior of illegal lane occupation. This indicated that riders with active, irritable, and extrovert personality were more likely to illegally occupy motor vehicle lanes.

During the process of e-bike riding, more than $80 \%$ of the information was collected by vision, and more than $90 \%$ of the information was dynamic. This relied heavily on the dynamic vision of the riders. The basis of dynamic vision is static vision, which lies at the root of cognition and judgment of the traffic environment. Corrected vision can meet the need for general information, but riders with corrected vision can still hardly have completely normal visual acuity. Moreover, the lens has a certain curvature, which causes mild deformation of the surrounding environment. This has a less significant impact on information acquisition when riding at a low speed in the motor vehicle lanes, but the impact can be considerable when riding at a high speed. As shown in Table 11, no significant difference in the mean for eye vision was observed on the four intervals, the value being about 0.183 . This indicated that the riders' vision had no significant impact on the choice of illegal lane occupation behavior. Furthermore, riders with corrected vision accounted only for a small proportion of all e-bike riders. This further indicated that riders wearing eyeglasses still could not have completely normal eye vision for recognizing the surrounding environment. The values of elasticity for eye vision on the four intervals were 0.046-0.070, which were all smaller than 1.000. This indicated the lack of elasticity of eye vision for the choice of illegal lane occupation behavior. Thus, whether riders had corrected vision had little impact on the behavior of occupying motor vehicle lanes.

5.1.4. Occupation and Cycling Proficiency. Table 12 presents the results for occupation and cycling proficiency. According to the table, the mean for occupation was 1.482, and no significant difference in the mean was found on 
TABLE 12: Calculation results on occupation and cycling proficiency.

\begin{tabular}{lccccccc}
\hline \multirow{2}{*}{ Interval for different lanes occupied } & \multirow{2}{*}{ Selection probability } & \multicolumn{2}{c}{ Occupation } & \multicolumn{3}{c}{ Cycling proficiency } \\
& & Parameter & Mean & Elasticity & Parameter & Mean & Elasticity \\
\hline A & 0.287 & 0.417 & 1.253 & 0.372 & 1.919 & 2.033 & 2.782 \\
B & 0.124 & 0.417 & 1.559 & 0.569 & 1.919 & 2.311 & 3.883 \\
C & 0.289 & 0.417 & 1.510 & 0.448 & 1.919 & 2.531 & 3.453 \\
D & 0.300 & 0.417 & 1.606 & 0.469 & 1.919 & 2.182 & 2.932 \\
\hline
\end{tabular}

intervals $\mathrm{B}, \mathrm{C}$, and $\mathrm{D}$. The mean on interval A was 1.253 , which was the smallest of all four intervals. This indicated that the number of students and employees was the highest of all riders illegally occupying motor vehicle lanes. In addition, they were more likely to occupy the nonmotor vehicle lane. Mean elasticity for occupation on the four intervals was 0.465 , with all values of elasticity less than 1.000 . This indicated that occupation had low elasticity on the choice of illegal lane occupation behavior. Therefore, the occupation had an insignificant impact on the choice of illegal lane occupation behavior.

Table 12 also shows that the mean for cycling proficiency increased steadily, the value being 2.264 . This indicated that riders more skillful with riding were more likely to occupy the motor vehicle lanes. The reason is that as the driving age accumulates, the riders become more familiar with the road environment and infrastructure. Therefore, they are better prepared physiologically and physically when choosing to occupy the motor vehicle lanes. Values of elasticity for cycling proficiency on the four intervals were all more than 1.000 , the value being 3.263 . This indicated that cycling proficiency had high elasticity for the choice of illegal lane occupation behavior. This indicated that the higher the cycling proficiency, the higher the probability that the riders occupied the motor vehicle lanes. Moreover, values of elasticity were higher in intervals $\mathrm{B}$ and $\mathrm{C}$, indicating that the cycling proficiency had the greatest impact on the choice of occupying the first (closer to the nonmotor vehicle lane) and second motor vehicle lanes. Relatively speaking, the probability that the riders occupied the third motor vehicle lane (closest to the middle isolation zone) was the smallest. The specific relationship between riding proficiency and behavior of illegal lane occupation is illustrated in Figure 5.

Figure 5 shows that the e-bike riders were more skillful with riding, and as the riding proficiency increased, an increasing number of riders occupied the motor vehicle lanes. This is because high riding proficiency is usually accompanied by richer driving age, better psychological quality, and higher demand for riding speed. For this reason, most of the e-bike riders would choose to occupy motor vehicle lanes with better road conditions. But when the riding proficiency reaches the highest, the number of violations decreases. This means experienced riders pay more attention to safety. In addition, the largest number of riders chose to occupy the nonmotor vehicle lane, to boost the traveling speed.

5.2. Correlation between Personal Characteristics, Traveling Speed, and Illegal Lane Occupation. Several different traffic groups use nonmotor vehicle lanes simultaneously, while the

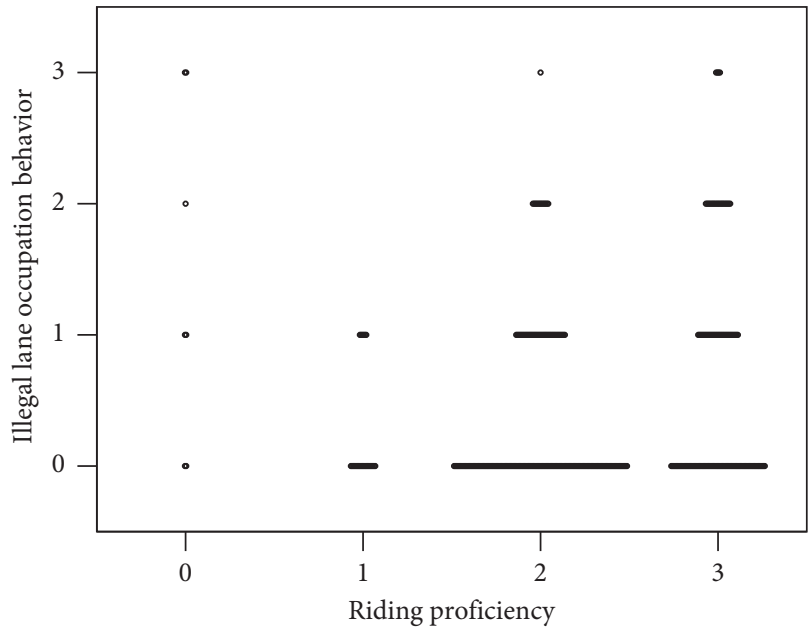

FIGURE 5: Relationship between riding proficiency and behavior of illegal lane occupation.

road infrastructure remains less developed compared with the motor vehicle lanes. Therefore, many e-bike riders prefer nonvehicle lanes for faster traveling or even overspeeding. Moreover, riders with different riding demand and riding habits occupy different positions of the motor vehicle lanes. In the present study, not only the influence of different personal characteristics of riders on the choice of traveling speed and illegal lane occupation behavior was analyzed but also the internal connections between the traveling speed of e-bike riders and the specific motor vehicle lane occupied were investigated.

e-bike riders prefer nonmotor vehicle lanes for the following reasons: the speed of the motor vehicle lane is much higher than the e-bike speed. There is a common sense that a slower one is easy to be hit by a faster one behind. So, the e-bike riders would not choose the motor vehicle lane to speed up, as that is obviously too dangerous. Although the nonmotor vehicle is narrow, pedestrians, bicycle, motorcycle, e-bike, and three-wheeler riders use the nonmotor vehicle lane simultaneously. It is safe than the motor vehicle lane. This directly results in lower traveling speed compared with the expectation on the part of e-bike riders. e-bikes need less space, which can basically meet the demand for traveling speed on the part of e-bike riders. Therefore, e-bike riders mostly prefer to occupy nonmotor vehicle lanes for faster movement. It can be inferred that illegal lane occupation correlates with overspeeding among e-bike riders, and such correlation is closely related to the personal characteristics of the riders. The specific relationship is shown in Figure 6. 


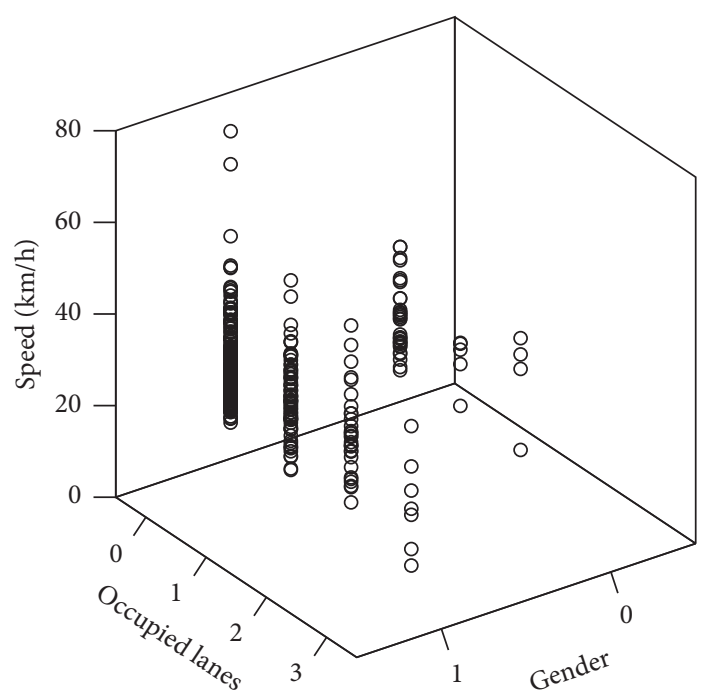

Figure 6: Relationship between traveling speed and illegal lane occupation behavior.

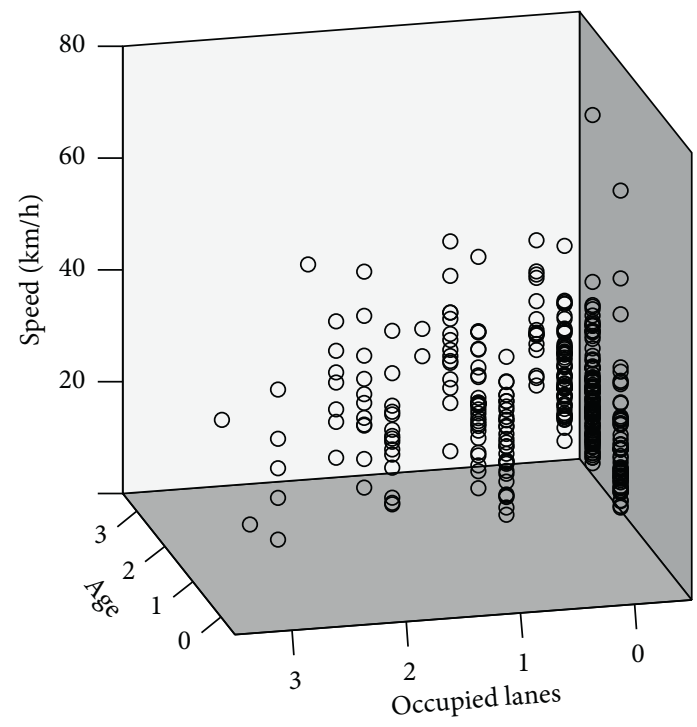

(a)

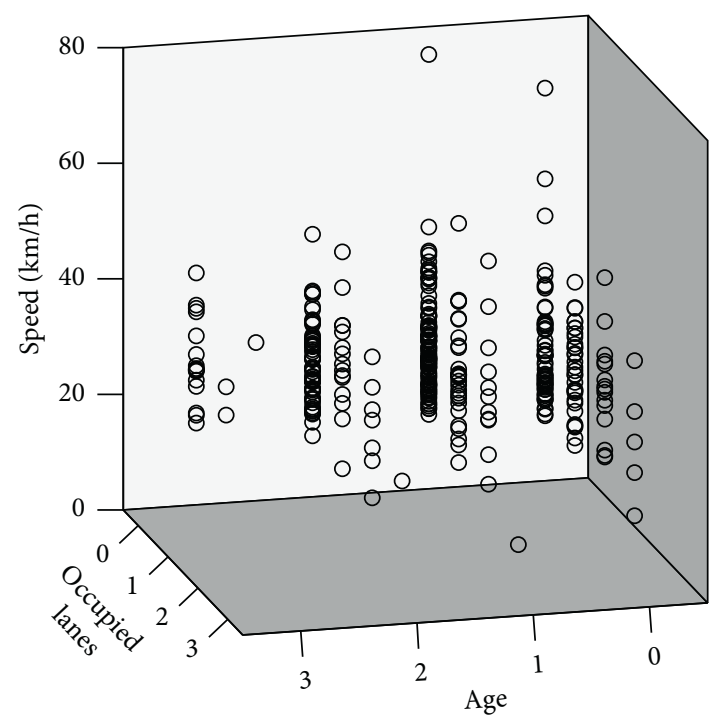

(b)

FIGURE 7: Relationship between age, traveling speed, and illegal lane occupation behavior.

Figure 6 shows that the majority of riders occupying the nonmotor vehicle lane were male, who traveled at the highest speed, which means overspeeding. It is easy to see that the largest number of male e-bike riders occupied the nonmotor vehicle lane for overspeeding.

Figure 7 shows that the age of riders occupying the nonmotor vehicle lane was about $30-45$ years, and this age group also had the highest traveling speed. Riders aged between 30 and 45 years more frequently chose the behavior of illegal lane occupation, and the number of riders occupying the first motor vehicle lane was the highest.

Figure 8 shows that riders with junior and senior high school educational levels were more likely to occupy the nonmotor vehicle lanes and to overspeed. Riders with university and higher educational level were less likely to occupy the motor vehicle lanes. This indicated that the safety awareness and traffic knowledge level of riders with high educational level were higher compared with those with lower educational level.

Figure 9 shows that riders with a driving age of 1-3 below a year were more likely to occupy the motor vehicle lanes, and the traveling speed was the highest in riders occupying the nonmotor vehicle lane. This indicated that e-bike riders with fewer riding years were most likely to overspeed in the nonmotor vehicle lane.

Figure 10 shows that of the four types of temperament examined, those with sanguine and lymphatic temperaments were more likely to occupy the nonmotor vehicle lanes and 


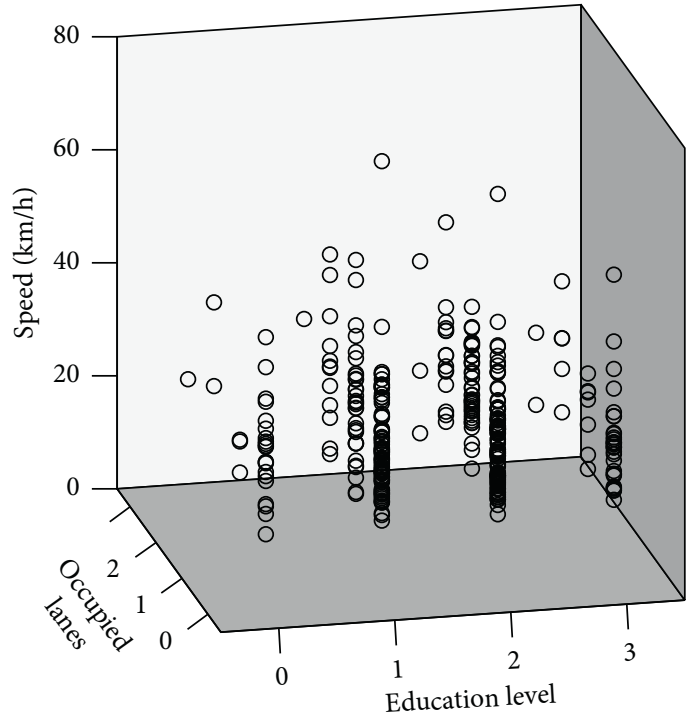

(a)

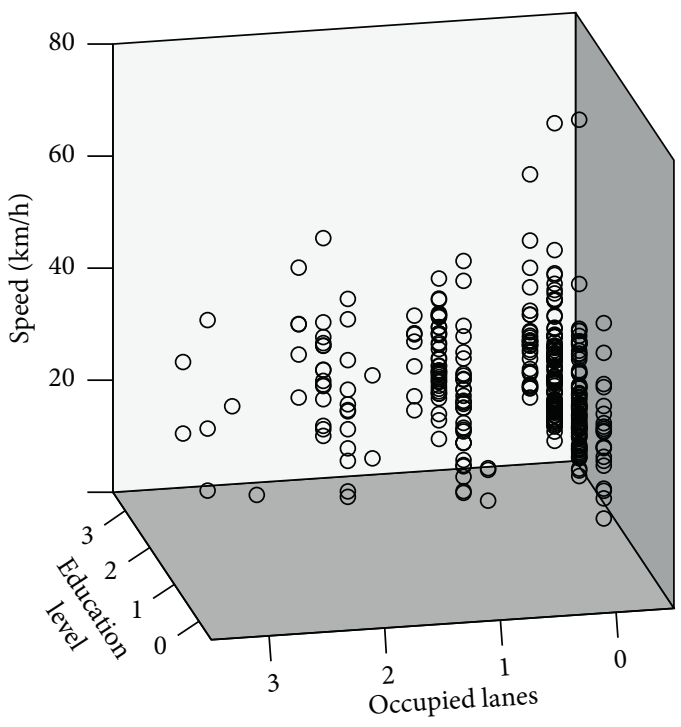

(b)

FIGURE 8: Relationship between the educational level, traveling speed, and illegal lane occupation behavior.

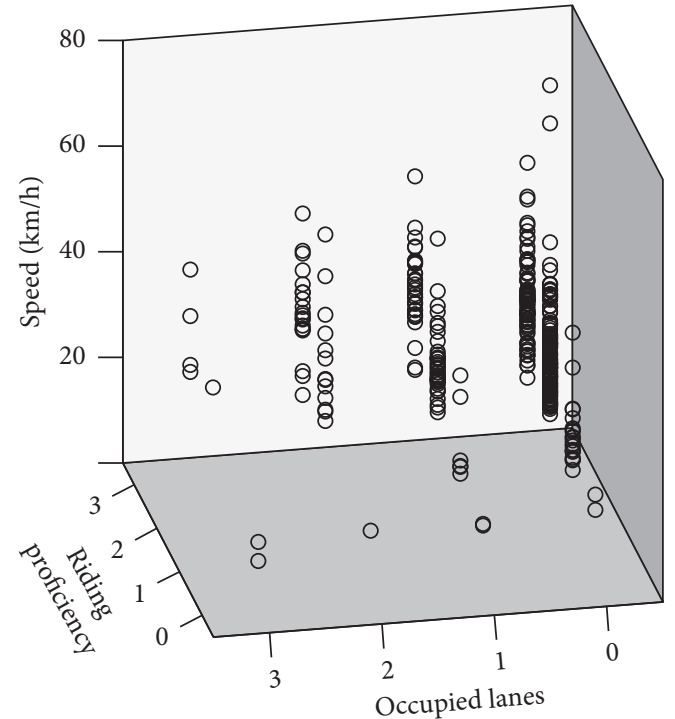

FIgURE 9: Relationship between driving age, traveling speed, and illegal lane occupation behavior.

to overspeed. The traveling speed of riders with lymphatic temperament occupying the nonmotor vehicle lane was the highest, exceeding $25 \mathrm{~km} / \mathrm{h}$, and the overspeeding behavior was most likely.

Figure 11 shows that it was most prevalent for employees to occupy motor vehicle lanes, and the employees occupying the nonmotor vehicle lane had the highest traveling speed. Relatively speaking, the traveling speed of retiree and students was lower. Very few students preferred traveling in the motor vehicle lanes, and their traveling speed was low. This was closely related to traffic safety awareness education and training at schools.

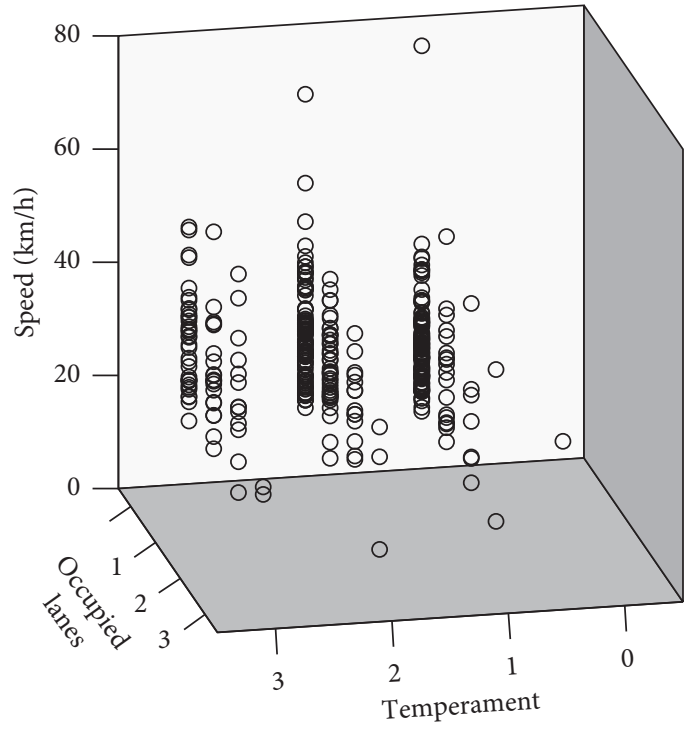

FIgURE 10: Relationship between temperament, traveling speed, and illegal lane occupation behavior.

Figure 12 shows that the number of riders without corrected vision was the highest among all riders illegally occupying the motor vehicle lanes. Such riders were more likely to occupy the first motor vehicle lane and nonmotor vehicle lane and travel at the highest speed. As a result, illegal riding behaviors, such as overspeeding, were frequent.

Figure 13 shows that as the riding age increased and driving age became more abundant, e-bike riders were more likely to occupy the non- and first motor vehicle lanes. Moreover, the traveling speed of riders occupying the nonmotor vehicle lane was the highest, leading to the highest risk of illegal riding behaviors, such as overspeeding. 


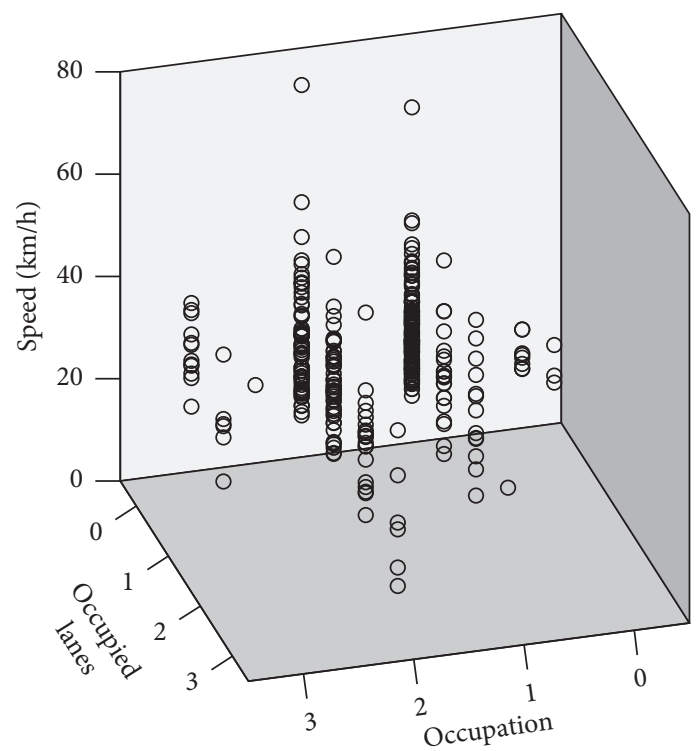

FIGURE 11: Relationship between occupation, traveling speed, and illegal lane occupation behavior.

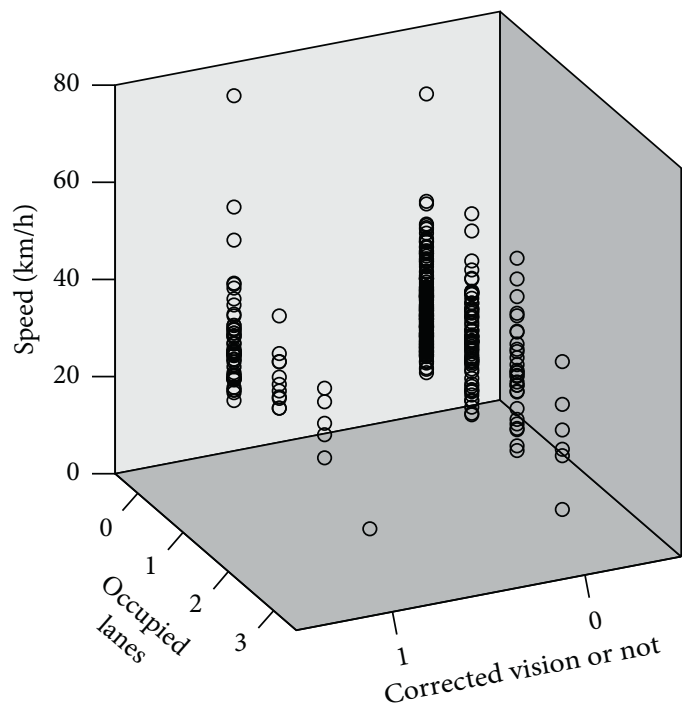

FIGURE 12: Relationship between eye vision, traveling speed, and illegal lane occupation behavior.

\section{Conclusions and Future Study}

6.1. Conclusions. Based on previous studies on traffic behaviors of e-bike riders, the influence of personal characteristics of e-bike riders and illegal lane occupation was further discussed. The specific personal characteristics influencing the choice of such illegal behavior were identified after measuring the correlation degrees. Moreover, concrete management strategies and schemes for safety education and skill training were proposed for e-bike riders with different personal characteristics. The ultimate purpose was to boost the traffic safety awareness of the riders and reduce risky riding behaviors and probability of traffic accidents. In this study, the temperament and cycling proficiency of riders significantly correlated with illegal riding behaviors. Therefore, effective regulatory measures should be formulated targeting these two aspects:

(1) The higher the riding proficiency of the e-bike riders, the higher the probability that the riders occupy the nonmotor vehicle lane, which poses a great threat to the riding safety. From another perspective, this highlights the importance of riding skills for ensuring safety. Therefore, traffic authorities should improve safety awareness and ethics for e-bike riders to ensure that every rider has enough skills and reduce inconvenience to pedestrians. Moreover, e-bike riders should wear protective equipment to minimize potential injury during riding. 


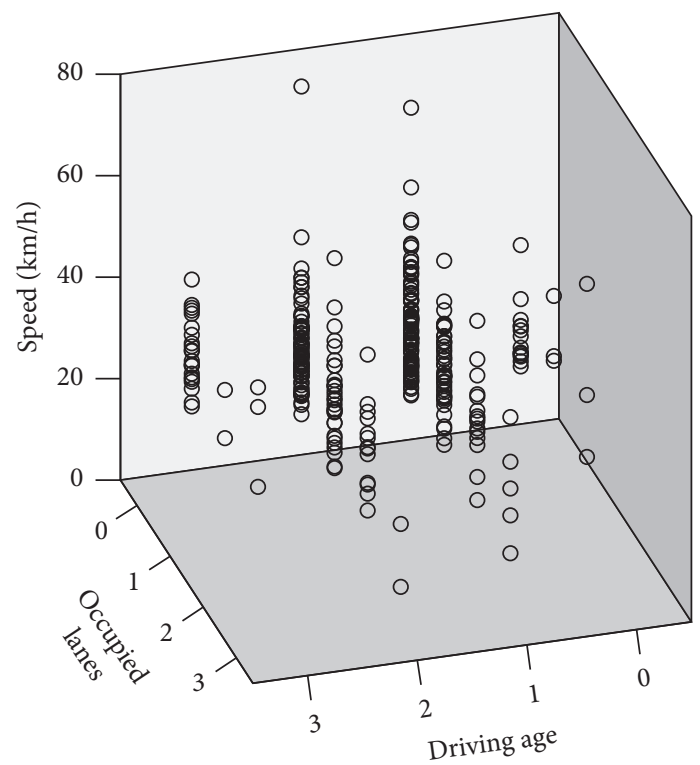

FIGURE 13: Relationship between driving age, traveling speed, and illegal lane occupation behavior.

(2) Traffic authorities should stop e-bike riders occupying nonmotor vehicle lanes on the road on a regular basis. These riders should be fined, and uniform safety education should be provided. In addition to safety precautions, these riders should be made to watch videos on traffic accidents of motor vehicles and those caused by illegal lane occupation to make them fully aware of the disadvantages of illegal lane occupation. Along with the safety education, webcast or road display should be used for notification on safety precautions for e-bike riders. While tightening law enforcement, all riders should be educated on the dangers of illegal lane occupation to boost safety awareness and safety riding behaviors.

(3) The root cause for illegal lane occupation is to achieve a faster speed. As indicated by the statistical analysis of sample data, it was found that the average traveling speed for riders occupying the second and third motor vehicle lanes was $25.1 \mathrm{~km} / \mathrm{h}$, which generally corresponded to overspeeding. Therefore, an illegal behavior warning device and a memory device should be installed on the e-bikes. These devices would transmit the riding data to traffic authorities in real time via the Internet. When e-bike riders overspeed in the nonmotor vehicle lane, voice prompts would remind the riders to travel at a safe speed. When e-bike riders overspeed in the nonmotor vehicle lane, not only voice prompts but also the rider information would be transmitted to the traffic authorities through the memory device. These riders would be singled out for safety education and penalty, so as to reduce the behaviors of illegal lane occupation and create a safe traffic environment.
In this study, first, the measurement model for assessing the influence of personal characteristics of electric vehicle riders on illegal lane behavior was built. The $t$-test was conducted indicating that the built model agreed well with the actual situation and had strong adaptability and practicability. Moreover, the model could quantify the degree of correlation between personal characteristics and illegal lane occupation. Second, elasticity theory was used to analyze the sensitivity of each influence factor to the choice of illegal lane occupation behavior. Finally, the influence of different personal characteristics of e-bike riders on risky riding behaviors was analyzed and the conclusions were drawn. The results showed that two personal characteristics, temperament and riding proficiency, had values of elasticity more than 1.000 for the choice of illegal lane occupation. In other words, these two influence factors were sensitive to the choice of illegal lane occupation behavior. Based on the riding speed obtained from the survey, the relationship between personal characteristics, traveling speed, and illegal lane occupation of e-bike riders was analyzed. As shown by analysis, riders with different personal characteristics traveled at different speeds on different lanes. The largest number of riders chose to travel in the first motor vehicle lane. The number of riders without corrected vision was also the highest among all riders occupying motor vehicle lanes. Riders with these characteristics were more likely to occupy the nonmotor vehicle lane and to overspeed.

6.2. Future Study. The sample values of this model had certain limitations, and the value range needs to be further expanded in future studies [48-51]. Moreover, other personal characteristics, such as marital status and body height, should also be included in the investigation. In addition, parameter values of each influence factor in the model need to be constantly modified so that the results of sensitivity 
analysis are more accurate and better agree with the actual traveling situation.

The disaggregate model used in the present study had strong adaptability to individuals' traffic behaviors and the results obtained were reliable. In future studies, structural equation modeling should be used for stratification of the influencing factors. Observable variables described in this study need to be considered to study the relationship between potential variables and illegal lane occupation by e-bike riders.

\section{Data Availability}

The data used to support the findings of this study are available from the corresponding author upon request.

\section{Conflicts of Interest}

The authors declare that they have no conflicts of interest regarding the publication of this paper.

\section{Acknowledgments}

This research was funded by the National Natural Science Foundation of China (Project no. 71861023), the Program of Humanities and Social Science of the Education Ministry of China (no. 18YJC630118), the Natural Science Foundation of Zhejiang Province (no. LQ19E080003), the Natural Science Foundation of Ningbo Municipality (no. 2018A610127), the Philosophy and Social Science Program of Ningbo (G20-ZX37), and the Foundation of A Hundred Youth Talents Training Program of Lanzhou Jiaotong University.

\section{References}

[1] C. Ma, D. Yang, J. Zhou, Z. Feng, and Q. Yuan, "Risk riding behaviors of urban e-bikes: a literature review," International Journal of Environmental Research and Public Health, vol. 16, no. 13, pp. 2308-2322, 2019.

[2] E. Fishman and C. Cherry, "E-bikes in the mainstream: reviewing a decade of research," Transport Reviews, vol. 36, no. 1, pp. 72-91, 2016.

[3] Y. Guo, J. Zhou, Y. Wu, and J. Chen, "Evaluation of factors affecting e-bike involved crash and e-bike license plate use in China using a bivariate probit model," Journal of Advanced Transportation, vol. 2017, Article ID 2142659, 12 pages, 2017.

[4] Y. Guo, Z. Li, Y. Wu, and C. Xu, "Evaluating factors affecting electric bike users' registration of license plate in China using Bayesian approach," Transportation Research Part F: Traffic Psychology and Behaviour, vol. 59, pp. 212-221, 2018.

[5] China News Network, "China's electric bicycles have a social holding capacity of 250 million vehicles," 2017, http://news. ddc.net.cn/newsview_71477.html.

[6] Sohu.com, "The number of electric vehicles in nanning has exceeded 1.8 million," 2018, http://www.sohu.com/a/ $229498412 \_394146$.

[7] Traffic Administration Bureau of the Ministry of Public Security, People's republic of China Annual Report of Road Traffic Accidents (2016), Traffic Management Bureau of the Ministry of Public Security, Beijing, China, 2017.
[8] Y. Guo, Y. Wu, J. Lu, and J. Zhou, "Modeling the unobserved heterogeneity in e-bike collision severity using full Bayesian random parameters multinomial logit regression," Sustainability, vol. 11, no. 7, pp. 2071-2084, 2019.

[9] Traffic Management Bureau of Ministry of Public Security, Statistics of Road Traffic Accidents in PRC (2015), Traffic Management Bureau of the Ministry of Public Security, Wuxi, China, 2016.

[10] F. Chen, S. Chen, and X. Ma, "Analysis of hourly crash likelihood using unbalanced panel data mixed logit model and real-time driving environmental big data," Journal of Safety Research, vol. 65, pp. 153-159, 2018.

[11] JSTV, "Nearly $70 \%$ of traffic accidents are related to electric bicycles," 2016, http://news.jstv.com/a/20160805/123632. shtml.

[12] W. Du, J. Yang, B. Powis et al., "Epidemiological profile of hospitalised injuries among electric bicycle riders admitted to a rural hospital in Suzhou: a cross-sectional study," Injury Prevention, vol. 20, no. 2, pp. 128-133, 2014.

[13] Compiled by national bureau of statistics of China," China Statistical Yearbook, China Statistics Press, Beijing, China, 2017.

[14] X. Ma, S. Chen, and F. Chen, "Multivariate space-time modeling of crash frequencies by injury severity levels," Analytic Methods in Accident Research, vol. 15, pp. 29-40, 2017.

[15] F. Hu, D. Lv, J. Zhu, and J. Fang, "Related risk factors for injury severity of e-bike and bicycle crashes in Hefei," Traffic Injury Prevention, vol. 15, no. 3, pp. 319-323, 2014.

[16] J. B. Zhou, Q. Y. Wang, M. J. Zhang, S. Dong, and S. C. Zhang, "An empirical study on seven factors influencing waiting endurance time of e-bike," Journal of Transportation Systems Engineering and Information Technology, vol. 17, no. 5, pp. 242-249, 2017.

[17] G. Ren, W. J. Wang, and Y. Zhang, Traffic Behavior Safety of Non-motorized Traffic Participants-Modeling, Evaluation and Decision-Making System, Science Press, Beijing, China, 2012.

[18] L. Yao and C. Wu, "Traffic safety for electric bike riders in China," Transportation Research Record: Journal of the Transportation Research Board, vol. 2314, no. 1, pp. 49-56, 2012.

[19] Y. Guo, P. Liu, L. Bai, C. Xu, and J. Chen, "Red light running behavior of electric bicycles at signalized intersections in China," Transportation Research Record: Journal of the Transportation Research Board, vol. 2468, no. 1, pp. 28-37, 2014.

[20] J. B. Zhou, Y. Y. Guo, W. U. Yao, and D. Sheng, "Assessing factors related to e-bike crash and e-bike license plate use," Journal of Transportation Systems Engineering and Information Technology, vol. 17, no. 3, pp. 229-234, 2017.

[21] C. X. Ma, J. B. Zhou, D. Yang, and Y. Y. Fan, "Research on the relationship between the individual characteristics of electric bike riders and illegal speeding behavior: a questionnairebased study," Sustainability, vol. 12, no. 3, pp. 1-12, 2020.

[22] L. Steg and A. v. Brussel, "Accidents, aberrant behaviours, and speeding of young moped riders," Transportation Research Part F: Traffic Psychology and Behaviour, vol. 12, no. 6, pp. 503-511, 2009.

[23] M. A. Elliott, C. J. Baughan, and B. F. Sexton, "Errors and violations in relation to motorcyclists' crash risk," Accident Analysis \& Prevention, vol. 29, no. 3, pp. 491-499, 2007.

[24] C. Q. Xie and P. Dianne, "A social psychological approach to driving violations in two Chinese cities," Transportation Research Part F: Traffic Psychology and Behaviour, vol. 5, no. 4, pp. 293-308, 2001. 
[25] P. Ulleberg and T. Rundmo, "Personality, attitudes and risk perception as predictors of risky driving behaviour among young drivers," Safety Science, vol. 41, no. 5, pp. 427-443, 2003.

[26] C.-F. Chen, "Personality, safety attitudes and risky driving behaviors-evidence from young Taiwanese motorcyclists," Accident Analysis \& Prevention, vol. 41, no. 5, pp. 963-968, 2009.

[27] J. P. Scheper, "The safety of electrically assisted bicycles compared to classic bicycles," Accident Analysis \& Prevention, vol. 73, pp. 174-190, 2014.

[28] J. Reason, A. Manstead, S. Stradling, J. Baxter, and K. Campbell, "Errors and violations on the roads: a real distinction," Ergonomics, vol. 33, no. 10-11, pp. 1315-1332, 1990.

[29] G. Konstantina, "Modeling motorcycle helmet use in Iowa: evidence from six roadside observational surveys," Accident Analysis \& Prevention, vol. 41, no. 3, pp. 479-484, 2009.

[30] L. T. Truong, H. T. T. Nguyen, and C. De Gruyter, "Mobile phone use among motorcyclists and electric bike riders: a case study of Hanoi, Vietnam," Accident Analysis \& Prevention, vol. 91, pp. 208-215, 2016.

[31] M. Huan, X. Yang, and B. Jia, "Crossing reliability of electric bike riders at urban intersections," Mathematical Problems in Engineering, vol. 2013, Article ID 108636, 8 pages, 2013.

[32] W. Du, J. Yang, B. Powis et al., "Understanding on-road practices of electric bike riders: an observational study in a developed city of China," Accident Analysis \& Prevention, vol. 59, pp. 319-326, 2013.

[33] M. Zhao, M. Yu, L. Fang et al., "Road-side observational survey on 4 unlawful acts among electric bicycle riders in Zhejiang," Chinese Journal of Epidemiology, vol. 37, no. 5, pp. 629-633, 2016.

[34] C. Wu, L. Yao, and K. Zhang, "The red-light running behavior of electric bike riders and cyclists at urban intersections in China: an observational study," Accident Analysis \& Prevention, vol. 49, pp. 186-192, 2012.

[35] J. P. Schepers, E. Fishman, P. den Hertog, K. K. Wolt, and A. L. Schwab, "The safety of electrically assisted bicycles compared to classic bicycles," Accident Analysis \& Prevention, vol. 73, pp. 174-180, 2014.

[36] T. Petzoldt, K. Schleinitz, S. Heilmann, and T. Gehlert, “Traffic conflicts and their contextual factors when riding conventional vs. electric bicycles," Transportation Research Part F: Traffic Psychology and Behaviour, vol. 46, pp. 477-490, 2017.

[37] M. Johnson and G. Rose, "Extending life on the bike: electric bike use by older Australians," Journal of Transport \& Health, vol. 2, no. 2, pp. 276-283, 2015.

[38] C. R. Cherry, J. X. Weinert, and Y. Xinmiao, "Comparative environmental impacts of electric bikes in China," Transportation Research Part D: Transport and Environment, vol. 14, no. 5, pp. 281-290, 2009.

[39] X. Xing, W. Xu, Y. Chen, Z. Liu, Z. Bian, and Y. Liu, “A roadside observation study of unsafe riding acts among electric bicycle riders in a city of Anhui province," Chinese Journal of Disease Control \& Prevention, vol. 21, pp. 943-946, 2017.

[40] H. Niu, X. Zhou, and X. Tian, "Coordinating assignment and routing decisions in transit vehicle schedules: a variablesplitting Lagrangian decomposition approach for solution symmetry breaking," Transportation Research Part B: Methodological, vol. 107, pp. 70-101, 2018.

[41] H. Niu, X. Zhou, and R. Gao, "Train scheduling for minimizing passenger waiting time with time-dependent demand and skip-stop patterns: nonlinear integer programming models with linear constraints," Transportation Research Part B: Methodological, vol. 76, pp. 117-135, 2015.

[42] F. Chen and S. Chen, "Injury severities of truck drivers in single- and multi-vehicle accidents on rural highways," Accident Analysis \& Prevention, vol. 43, no. 5, pp. 1677-1688, 2011.

[43] Y. Guo, Z. Li, P. Liu, and Y. Wu, "Modeling correlation and heterogeneity in crash rates by collision types using full Bayesian random parameters multivariate Tobit model," Accident Analysis \& Prevention, vol. 128, pp. 164-174, 2019.

[44] C. Ma, W. Hao, W. Xiang, and W. Yan, "The impact of aggressive driving behavior on driver-injury severity at highway-rail grade crossings accidents," Journal of Advanced Transportation, vol. 2018, pp. 1-10, 2018, 2018.

[45] GB17761-2018, "Electric bicycle safety technical specifications," Electric Bicycle Safety Technical Specifications, State Market Supervisory Administration/China National Standardization Administration, Beijing, China, 2018.

[46] S. Wu and F. M. Pan, Statistical Analysis of SPSS, Tsinghua University Press, Beijing, China, 2017.

[47] H. Niu, X. Tian, and X. Zhou, "Demand-driven train schedule synchronization for high-speed rail lines," IEEE Transactions on Intelligent Transportation Systems, vol. 16, no. 5, pp. 2642-2652, 2015.

[48] C. Ma, Changxi, R. He, and W. Zhang, "Path optimization of taxi carpooling," PLoS One, vol. 13, no. 8, Article ID e0203221, 2018.

[49] C. Ma, W. Hao, A. Wang, and H. Zhao, "Developing a coordinated signal control system for urban ring road under the vehicle-infrastructure connected environment," IEEE Access, vol. 6, pp. 52471-52478, 2018.

[50] C. Ma, "Network optimisation design of hazmat based on multi-objective genetic algorithm under the uncertain environment," International Journal of Bio-Inspired Computation, vol. 12, no. 4, pp. 236-244, 2018.

[51] C. Ma, W. Hao, F. Pan, and W. Xiang, "Road screening and distribution route multi-objective robust optimization for hazardous materials based on neural network and genetic algorithm," PLoS One, vol. 13, no. 6, Article ID e0198931, 2018. 